J. Lake Sci.(湖泊科学), 2009, 21(5): 669-674

http://www.jlakes.org. E-mail: jlakes@niglas.ac.cn

(C2009 by Journal of Lake Sciences

\title{
两种改性粘土去除群体状铜绿微囊藻的比较*
}

田 娟 ${ }^{1,2}$, 宋碧玉 ${ }^{2}$, 林 炎 ${ }^{1}$, 余博识 ${ }^{1}$, 李仁辉 ${ }^{* *}$

(1: 中国科学院水生生物研究所, 武汉 430072)

(2: 武汉大学资源与环境科学学院, 武汉 430079)

摘 要: 实验采用壳聚糖和聚合氯化铝改性高岭土, 进行以铜绿微囊藻为优势种的水华蓝藻去除的比较研究. 研究采用动 力学手段, 通过去除效率的比较, 得到线性方程: 壳聚糖改性高岭土投加量 $(y)$ 与藻细胞浓度 $\mathrm{OD}_{680}(x)$ 和叶绿素 $\mathrm{a}$ 含量 $(x)$ 之 间的关系分别为: $y=0.0349 x-0.0019 、 y=0.0524 x-0.009$; 聚合氯化铝改性高岭土投加量 $(y)$ 与藻细胞浓度 $\mathrm{OD}_{680}(x)$ 和叶绿素 $\mathrm{a}$ 含量 $(x)$ 之间的关系分别为: $y=0.0351 x+0.0065 、 y=0.0676 x-0.0059$. 壳聚糖改性粘土除藻的最适 $\mathrm{pH}$ 范围为 $5-8$, 聚合氯 化铝改性粘土除藻的最适 $\mathrm{pH}$ 范围为 5-9, pH 范围相对较宽. 电子传递速率分析表明壳聚糖改性粘土处理后 1 个月内藻趋 于死亡, 聚合氯化铝改性粘土处理过的藻, 一周内藻开始黄化, 衰老.

关键词：聚合氯化铝; 壳聚糖; 改性粘土; 絮凝; 铜绿微囊藻; 水华

\section{Removal of colonial Microcystis aeruginosa using two kinds of modified clays}

\author{
TIAN Juan ${ }^{1,2}$, SONG Biyu ${ }^{2}$, LIN Shen ${ }^{1}$, YU Boshi $^{1} \&$ LI Renhui ${ }^{1}$ \\ (1: Institute of Hydrobiology, Chinese Academy of Sciences, Wuhan 430072, P.R.China) \\ (2: School of Resource and Envirionmental Science, Wuhan University, Wuhan 430079, P.R.China)
}

Abstract: Microcystis waterbloom always occurs in colonial forms in natural waters. However, most laboratory studies on removal of Microcystis cells by various approaches were performed by using single-cell Microcystis strains. This study aimed to remove Microcystis aeruginosa, as the dominant species in Chinese waters, by Chitosan and Polymeric Aluminum Chloride (PAC) modified clays(Kaolin). Using colonial Microcystis aeruginosa strain HAB 657, the relationships between the quantity of the chitosan modified clays $(y)$ and $\operatorname{OD}_{680}(x)$ and between the quantity of the chitosan modified clays $(y)$ and the concentration of chlorophyll-a(Chl.a) $(x)$ was expressed as $y=0.0349 x-0.0019$ and $y=0.0524 x-0.009$, respectively. While relationships between the quantity of the PAC modified clays $(y)$ and the $\operatorname{OD}_{680}(x)$, and between the quantity of the PAC modified clays $(y)$ and the Chl.a $(x)$ content were expressed as $y=0.0351 x+0.0065$ and $y=0.0676 x-0.0059$ respectively. It showed that the optimal $\mathrm{pH}$ ranged from 5 to 8 for chitosan modified clays to remove Microcystis cells, and PAC modified clays with 5-9 optimal pH. Analysis of Electron Transport Rate (ETR) showed that sedimented Microcystis cells became yellowish and decayed in a week after treatment by PAC modified clay, and were dead in one month after the treatment of chitosan modified clays.

Keywords: PAC; chitosan; modified clays; flocculation; Microcystis aeruginosa; algal bloom

自然水体富营养化和蓝藻水华的频繁暴发已成为全世界所面临的重大环境问题，我国的情况也非常 严峻, 继无锡太湖, 云南滇池和安徽巢湖之后，长春新立城水库、武汉东湖部分湾区也相继爆发严重的蓝 藻水华 ${ }^{[1]}$. 蓝藻水华的暴发对水产养殖业、景观旅游业等构成了严重的影响. 有研究表明暴发的蓝藻水华 中有 $80 \%$ 是产生毒素的 ${ }^{[2]}$, 而这些毒素既可以直接进人饮水源危害人类健康，也可以通过食物链在水生

* 中国科学院 “百人计划” 项目(082303-1-501)资助. 2008-12-16 收稿; 2009-03-10 收修改稿. 田娟, 女, 1984 年生, 硕士 研究生; E-mail: tianjuan01@163.com.

** 通讯作者; E-mail: reli@ihb.ac.cn 
动物如水产品中富集，从而间接的威胁到人类的健康. 因此选择一种高效、简易、环保、廉价、不产生 二次污染的治理蓝藻水华的方法是当下亟需解决的课题. 目前治理蓝藻水华的方法有多种, 利用天然粘 土矿物治理藻华污染是目前颇具前景的一个发展方向. 粘土矿物作为天然的藻絮凝剂有较高的效能, 其 来源充足, 成本低廉, 无毒无污染, 对其它生物的影响也较小.

蓝藻水华只有在合适的气候条件下才会形成, 其潜伏期长、爆发突然的特点. 使治理蓝藻水华的应

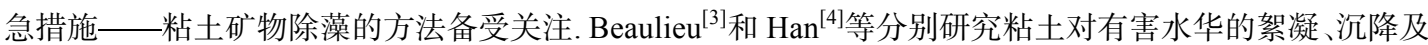
去除，指出 $\mathrm{pH}$ 值、藻细胞大小与粘土颗粒的接近程度和 Zeta 电位均影响藻的去除效率. 邹华等 ${ }^{[5]}$ 报道了 壳聚糖改性粘土对水华优势澡——铜绿微囊藻的絮凝去除的研究; 潘纲等 ${ }^{[6-7]}$ 在总结比较了 26 种粘土除 藻效率的基础上，提出了改性粘土除藻的粘结架桥机理、同时比较了壳聚糖改性膨润土和壳聚糖改性高 岭土絮凝除藻, 并提出采用当地粘土对蓝藻水华原位去除修复理论. 以上对微囊藻的研究都是建立在实 验室对单细胞形态的微囊藻藻种(FACHB469)研究的基础上, 但是对粘土处理后微囊藻藻体自身的生理 变化缺乏关注. 对于一些实际水体懪发的蓝藻水华是以群体形态存在, 其特定的群落特性及群体效应会 不会影响去除效果有待研究. 另外考虑到经济上的适用性，对于一些特定用途的水体要有针对性的采用 去除蓝藻水华的方法，对于景观用水或者非接触类水域考虑到经济上的实用性，采用高效、廉价的改性 剂同样可以达到去除效果. 此外通过改性粘土絮凝沉降后，对藻细胞活性的影响，以及会不会导致沉降 后的藻细胞破裂，从而大量释放胞内物质产生二次污染等问题都有待于进一步的研究. 本研究从实际情 况出发，以最近野外分离得到的群体微囊藻为研究对象，在实验室可控制的条件下，选取两种经济实用 性、且具技术推广性的改性剂: 壳聚糖和聚合氯化铝，比较两种改性粘土去除我国常见的蓝藻水华优势 种一一铜绿微囊藻的研究, 通过对两者改性粘土去除蓝藻水华的最佳投加量、最适 $\mathrm{pH}$ 范围及改性粘土处 理前后藻细胞活性的比较, 为蓝藻水华的治理工作提供一些更加详细的参数以补充粘土除藻的部分空白, 并提供相应的理论指导.

\section{1 材料与方法}

\section{1 藻种}

实验选用分离于新疆乌伦古湖的群体态铜绿微囊藻(Microcystis aeruginosa HAB657)为研究对象. 藻 种保存于中国科学院水生生物研究所有害藻类藻种库 $(\mathrm{HAB}$ ). 将藻液接人 $250 \mathrm{ml}$ 锥形瓶( 内盛 $150 \mathrm{ml} \mathrm{MA}$ 培养基)中静置培养, 每日早晚摇匀使不贴壁生长, 光照强度为 $25 \mu \mathrm{E} /\left(\mathrm{m}^{2} \cdot \mathrm{s}\right)$, 光暗周期为 $12: 12 \mathrm{~h}$, 温度为 $(25 \pm 1)^{\circ} \mathrm{C}$, 进行逐级扩大培养. 取接种后 7-8d, 处于指数生长期的铜绿微囊藻作为实验材料.

\section{2 粘土及改性剂}

粘土：高岭土; 改性剂: 壳聚糖(Chitosan)和聚合氯化铝(PAC).

改性粘土的制备: 改性粘土又称改性粘土溶液, 其中改性剂与粘土在溶液中的含量按 1:10的比例配 制 ${ }^{[8]}$, 含量为 $11 \mathrm{mg} / \mathrm{ml}$ (粘土含量为 $10 \mathrm{mg} / \mathrm{ml}$, 改性剂含量为 $1 \mathrm{mg} / \mathrm{ml}$ ). 称取 $100 \mathrm{mg}$ 改性剂, 加人 $10 \mathrm{ml} 1 \%$ 的 $\mathrm{HCl}$ 溶液不断振荡或摚拌使之溶解, 然后加蒸馏水至 $100 \mathrm{ml}$, 得到 $1 \mathrm{mg} / \mathrm{ml}$ 的改性剂盐酸溶液. 称取 $1 \mathrm{~g}$ 高岭 土加人已经配制好的 $100 \mathrm{ml}$ 的改性剂盐酸溶液中搅拌均匀，配制成改性粘土.

\section{3 藻类生物量的测定}

本研究以光密度 $\left(\mathrm{OD}_{680}\right)$ 和藻细胞计数两方面的指标来评判粘土沉降效果. 采用 721 型可见分光光度 计测定 $680 \mathrm{~nm}$ 波长下光吸收值, 即 $\mathrm{OD}_{680}$. 通过对比不同时间藻液的 $\mathrm{OD}_{680}$ 的值来衡量除藻效果. 用浮游 生物计数框(又称藻类计数框 $0.1 \mathrm{ml}$ ) 计数, 结果以每毫升水中藻细胞数表示.

\section{4 叶绿素 a 含量}

叶绿素 a 含量的测定，采用 90\%丙酮抽提(SL88-1994)的方法.

\section{5 光反应曲线(Light Response Curve)和电子传递速率}

以浮游植物荧光分析仪(PHYTO-PAM, Waltz公司，德国)检测对照和沉降后的铜绿微囊藻光合系统 II (PS II) 饱和脉冲光强下叶绿素菼光值的变化，计算PS II 的有效量子产率(Effective Quantum Yields, Y)和 电子传递速率(ETR, 单位: $\mu \mathrm{mol}$ electrons $\left./\left(\mathrm{cm}^{2} \cdot \mathrm{s}\right)\right)^{[9]}$. 


$$
Y=\triangle F / F m^{\prime}=\left(F t-F m^{\prime}\right) / F m^{\prime} ; E T R=0.5 Y \times P A R \times A F
$$

式中: $F m$ '为饱和脉冲光下的最大苂光; $F t$ 为作用光下实时苂光; $P A R$ 为光合活性辐射; $A F$ 为叶绿素对光照 的吸收效率, 值为 0.84 .

\section{6 去除率}

用去除率(Removal Rate, Rt)表示除藻的去除效率 ${ }^{[10],} R t$ 表示在单位时间内去除单位体积的藻细胞个 数, $R t$ 越大表示藻细胞去除效果越好.

$$
R t=\mathrm{d} Q_{t} / \mathrm{d} t=-0.5 Q_{0} \times k \times t^{-1 / 2} \times \exp \left(k t^{1 / 2}\right) ; Q_{t}=Q_{0}\left[1-\exp \left(k t^{1 / 2}\right)\right]
$$

式中: $R t$ 为去除率 $(\mathrm{cells} /(\mathrm{ml} \cdot \mathrm{min})) ; Q_{0}$ 为初始藻细胞个数 $($ cells $/ \mathrm{ml}) ; Q_{t}$ 为 $t$ 时间去除藻细胞个数 $(\mathrm{cells} / \mathrm{ml}) ; k$ 为絮凝常数; $t$ 为时间 (min).

\section{7 粘土去除藻类实验}

实验采用 $200 \mathrm{ml}$ 系列浓度梯度的藻液 (采用叶绿素 $\mathrm{a}$ 浓度 $(\mathrm{mg} / \mathrm{L}$ )为研究参数)为研究对象. 加人预先配 制好的改性粘土溶液, 进行絮凝沉降实验. 实验时, 先快摚 $3 \mathrm{~min}$, 再慢摚 $5 \mathrm{~min}$, 待藻液静置 $100 \mathrm{~min}$ 后, 取 表层藻液,测定 $\mathrm{OD}_{680}$ 、藻细胞个数等各项指标. 以Rt来衡量去除效率, 从系列浓度藻液不同的改性粘土投 加量所得的 $R t$ 中, 选取最大的 $R t$ 值, 并将这种连续性进行线性拟合, 得出改性粘土去除蓝藻水华的拟合 曲线.

\section{2 结果}

\section{1 不同藻细胞浓度最佳投入量的研究}

2.1 .1 壳聚糖改性高岭土 选取 $200 \mathrm{ml}$ 浓度梯度的藻液进行壳聚糖改性粘土的絮凝沉降实验，叶绿素 a 含 量分别为: $0.19 \mathrm{mg} / \mathrm{L} 、 0.27 \mathrm{mg} / \mathrm{L} 、 0.38 \mathrm{mg} / \mathrm{L} 、 0.64 \mathrm{mg} / \mathrm{L}$. 投加不同量的壳聚糖改性粘土，经过絮凝沉降实 验, 测定沉降前后各项指标. 通过去除率的观察和比较, 得到这 4 种藻浓度的最佳 $R t$ 所选取的最适粘土 溶液投加量分别为: $0.5 \mathrm{ml} 、 0.8 \mathrm{ml} 、 2.0 \mathrm{ml} 、 5.0 \mathrm{ml}$.

2.1.2 聚合氯化铝改性高岭土 聚合氯化铝改性粘土，用同壳聚糖改性粘土同样的方法对其除藻效率进行 研究. 实验采用, $200 \mathrm{ml}$ 系列浓度梯度的藻液 $0.19 、 0.43 、 0.72 、 1.1 \mathrm{mg} \mathrm{Chl.a/L}$ 为研究对象, 通过实验对藻 类去除率的比较, 得到这四种藻浓度的最佳 $R t$ 所选取的最适粘土溶液投加量分别为: $2.0 \mathrm{ml} 、 4.0 \mathrm{ml} 、 8.0 \mathrm{ml}$ 、 $14.0 \mathrm{ml}$.

\section{2 两种改性粘土除藻拟合曲线}

由以上两种改性粘土对不同生物量藻类水华的絮凝沉降, 得到的系列藻液最佳投人量. 其中生物量 以藻类的光密度 $\left(\mathrm{OD}_{680}\right)$ 和叶绿素 $\mathrm{a}$ 浓度分别对粘土的投加量的关系得到拟合曲线(图 1).

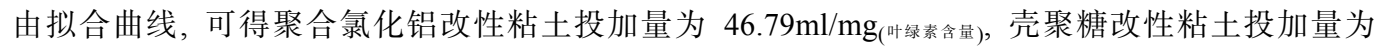

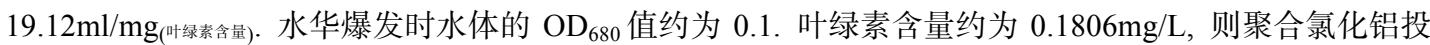
加量为 $8.45 \mathrm{ml} / \mathrm{L}$, 壳聚糖投加量为 $3.45 \mathrm{ml} / \mathrm{L}$. 处理相同生物量的蓝藻水华时, 壳聚糖改性粘土的投加量较 聚合氯化铝改性粘土的投加量少, 后者是前者的 2.45 倍.

\section{$2.3 \mathrm{pH}$ 对处理效果的影响}

选取 pH 5-10 为研究范围. 由藻液的 $\mathrm{OD}_{680}$ 表示, 根据拟合曲线投加相应体积浓度的改性粘土, 进行 絮凝沉降实验. 研究表明(图 2), 壳聚糖改性粘土除藻的最佳 $\mathrm{pH}$ 范围为 5-8, 聚合氯化铝改性粘土除藻的 最适 $\mathrm{pH}$ 范围相对较宽为 5-9. 两种改性粘土的投加量均遵循相应的拟合曲线.

\section{4 沉降处理后藻细胞活性}

对壳聚糖改性粘土沉降处理后的微囊藻，测定不同光强下的电子传递速率，得到光反应曲线(图 3a): 壳聚糖改性粘土去除铜绿微囊藻，沉降下来的微囊藻在最初 $8 \mathrm{~d}$ 的时间内其电子传递速率，因为絮凝成较 大的絮凝团聚集于底部，测得的最大电子传递速率高于对照，但是随着时间的增加，测得沉降第 $9 \mathrm{~d}$ 实验 组和对照组的最大电子传递速率分别为 $138.1 \mu \mathrm{mol}$ electrons $/\left(\mathrm{cm}^{2} \cdot \mathrm{s}\right)$ 和 $99.6 \mu \mathrm{mol}$ electrons $/\left(\mathrm{cm}^{2} \cdot \mathrm{s}\right)$, 表明实 验组的藻细胞活性从第 $9 \mathrm{~d}$ 开始低于对照组. 第 $30 \mathrm{~d}$ 测定沉降在底部的藻絮凝团的最大电子传递速率降低 至 $23.9 \mu \mathrm{mol}$ electrons $/\left(\mathrm{cm}^{2} \cdot \mathrm{s}\right)$, 藻的光学活性明显的降低, 与对照相比, 藻体发黄趋于死亡. 对聚合氯化 
铝沉降处理后的藻, 得到的光反应曲线(图 3b)表明, 沉降处理 $7 \mathrm{~d}$ 后藻体发黄, 最大电子传递速率为 $20.6 \mu \mathrm{mol}$ electrons $/\left(\mathrm{cm}^{2} \cdot \mathrm{s}\right)$, 较实验组 $97.2 \mu \mathrm{mol}$ electrons $/\left(\mathrm{cm}^{2} \cdot \mathrm{s}\right)$ 明显降低, 处理 $7 \mathrm{~d}$ 后, 藻的光合系统活性 显著降低.
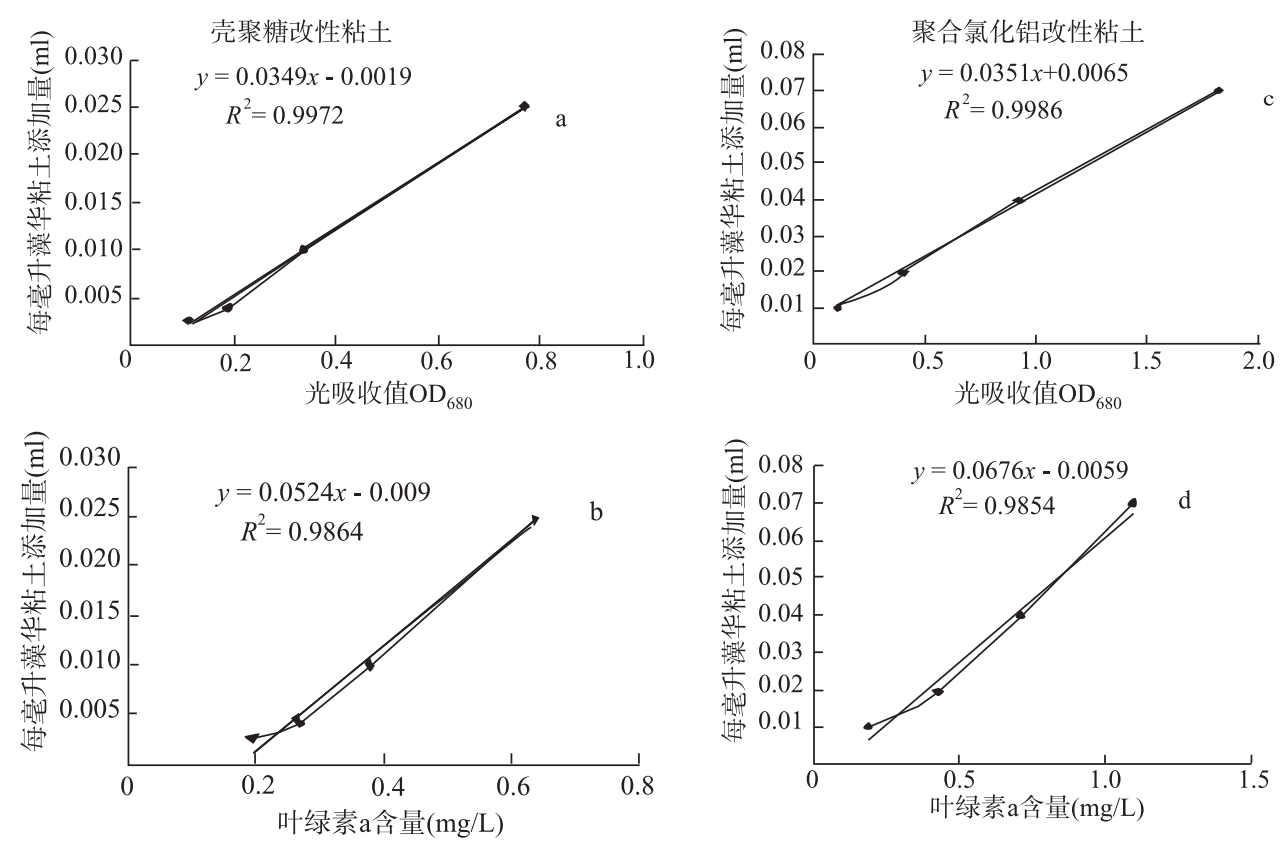

图 12 种改性粘土除藻拟合曲线

Fig.1 The fitting curve of two modified clays for algal removal
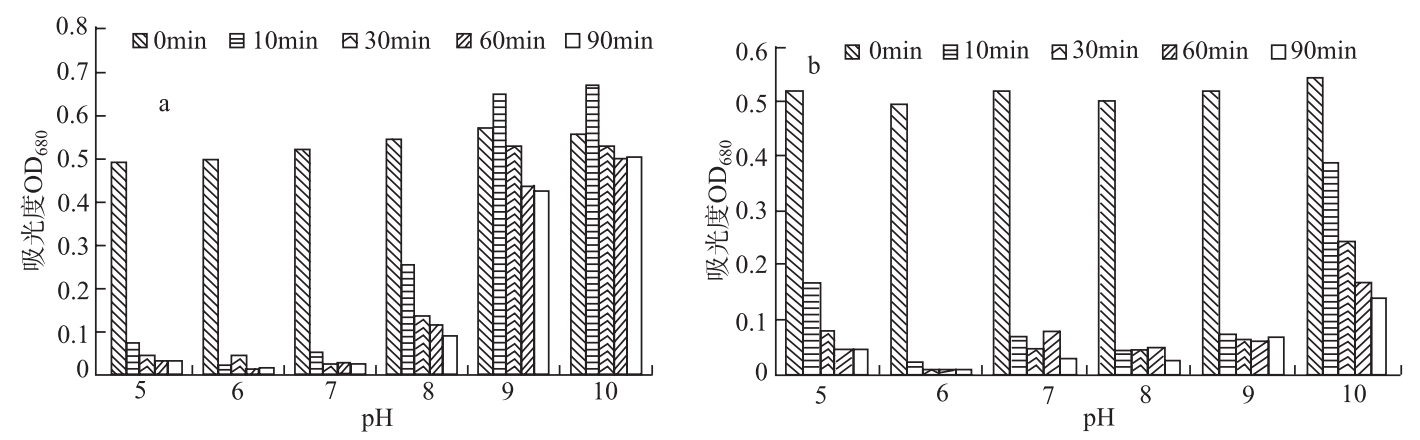

图 $2 \mathrm{pH}$ 对壳聚糖改性粘土(a)和聚合氯化铝改性粘土(b)除藻影响

Fig.2 Effect of $\mathrm{pH}$ on the removal of algal cells by Chitosan(a) and PAC(b) modified clays

\section{3 讨论}

本研究的特点是选用新近分离的铜绿微囊藻藻株为研究对象, 此藻株具有明显的大群体结构, 这样 的微囊藻形态结构更接近于自然水体的微囊藻水华的群体结构. 群体胶被透明无色, 群体具穿孔, 细胞 球形或近球形, 直径 3-7 $\mu \mathrm{m}$, 蓝绿色, 细胞具气囊(伪空胞)不宜沉降. 选取接种后 7-8d 处于对数生长期的 藻进行实验, 该阶段的藻细胞各项生命活动及机能维持在较高的水平, 具有较好的典型性. 研究采用动 力学的方法衡量除藻效果, 从而得到最佳粘土投放量. 通过去除率比较过程实验, 突出单位时间内藻细 胞去除的动态变化, 更形象的表示改性粘土除藻的及时性、实用性及可行性. 特别是实验得到蓝藻水华 生物量同投放粘土的拟合曲线, 可以为以后的蓝藻水华粘土治理的大规模使用提供投放量的参考依据. 

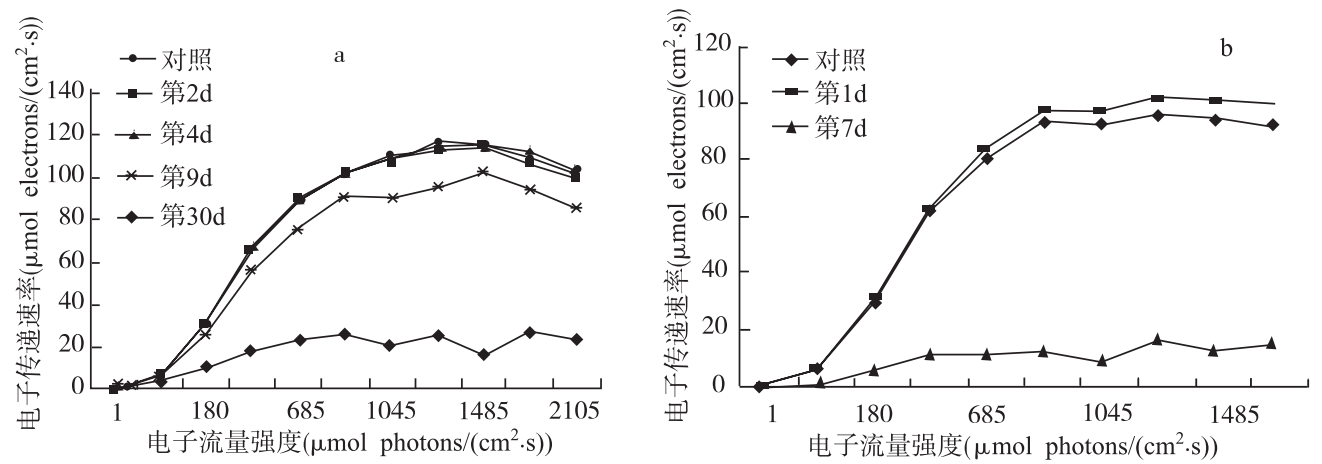

图 3 壳聚糖改性粘土(a)和聚合氯化铝改性粘土(b)处理前后藻细胞电子传递速率曲线

Fig.3 Comparison on ETR curve of algal cells before and after treatment by Chitosan(a) and PAC(b) modified clays

叶绿素苂光是光合作用的良好指标, 量子产量(Y)和 PAR 计算出的 PS II 的 ETR 在光饱和区达到最 大值即: ETR max $_{\text {m }}$ ETR 是 PS II 有效的光化学产率的产物 ${ }^{[11]}$, 其值反映了光合活性的大小 ${ }^{[12-13]}$, 并在一定 程度上决定了植物的生长速率 ${ }^{[14]}$. 研究发现, 壳聚糖改性粘土沉降的藻絮团, 在最初的几天内平均电 子传递速率 ETR 和最大电子传递速率 ETR $_{\text {max }}$ 都高于对照组, 表明絮凝下来的藻团, 由于团体效应, 其 光合系统特别是 PS II 系统的高活性. 这种粘结架桥机理除藻, 经过 $30 \mathrm{~d}$ 左右的观察, 高活性的光合系 统和高效的电子传递链, 在胁迫情况下, 藻团的生长速率受到抑制, 藻体发黄, 趋于死亡. 对于聚合氯 化铝改性粘土沉降的藻絮团, 时间为 $7 \mathrm{~d}$ 左右藻趋于老化、死亡. 沉降处理后的藻细胞进行光学显微镜 观察, 未见细胞破裂现象. 说明改性粘土沉藻是一种环境友好型除藻方法, 短时间内不会引起胞内氮 磷及毒素的大量释放.

对于改性粘土最佳投加量的研究, 邹华等 ${ }^{[5]}$ 研究壳聚糖改性粘土对单细胞的铜绿微囊藻的去除效果 的最佳投加量为 $11 \mathrm{mg} / \mathrm{L}$, 最适 $\mathrm{pH}$ 为 6-9. Zou et al ${ }^{[6]}$ 以及 Pan et $a l^{[7]}$ 研究壳聚糖改性海泡石和改性底泥原位 去除太湖野外微囊藻水华的最佳投加量同样为 $11 \mathrm{mg} / \mathrm{L}$. 但是, 张木兰等 ${ }^{[15]}$ 研究改性沉积物对巢湖蓝藻水 华去除研究时, 所用的投放量为 $43 \mathrm{mg} / \mathrm{L}$. 而本研究所得到的壳聚糖改性高岭土最佳投加量为 $38 \mathrm{mg} / \mathrm{L}$, 最 适 $\mathrm{pH}$ 为 5-8. 聚合氯化铝改性高岭土最佳投加量为 $93 \mathrm{mg} / \mathrm{L}$ ，最适 $\mathrm{pH}$ 为 5-9. 分析所得结果，本研究同潘刚 研究小组的差异性可能是由于本实验中使用群体微囊藻所产生的群体效应, 可以推测, 改性粘土对单细 胞和群体微囊藻的去除效果截然不同. 另外, 张木兰等的结果说明不同野外水体的蓝藻水华由于水华蓝 藻种类和比例的不同，也会导致有效投放量的巨大差异. 因此，针对不同水体暴发的蓝藻水华，建议在 共性研究的基础上有针对性的建立一些具体的参数, 为后续的研究提供理论上的指导意义. 对比水处理 中壳聚糖适宜的酸碱度范围为 $5-9^{[8]}$, 水华爆发时水体 $\mathrm{pH}$ 范围一般为 $8-10$, 考虑到工程上的实用性通常 会直接用改性粘土, 或稍稍加些刺激性较小的酸性物质如醋酸, 腐植酸 ${ }^{16]}$ 等作为除藻的预处理. 絮凝沉 降的过程中, 由于聚合氯化铝分子链及化学性质的影响, 形成的絮团较壳聚糖改性粘土松散, 但是在经 过一定的时间两者的去除效果相当. 聚合氯化铝改性粘土的投加量相对较多, 但是较廉价. 对于一些养 殖水体暴发蓝藻水华, 考虑到食品安全健康问题, 采用壳聚糖改性粘土进行水华的治理工作. 而对于一 些非养殖水体, 例如景观水体, 采用聚合氯化铝改性粘土即可满足水华去除, 廉价易得效果又显著.

改性粘土除藻是一个环境友好型的处理方法, 具有较好的经济和社会效益, 本研究对两种改性粘土 进行研究比较, 提出了线性拟合方程, 补充了粘土除藻的部分理论空白. 为今后的研究, 水华的治理工 作及生态保护提供很好的理论基础.

致谢: 感谢中国科学院水生生物研究所有害藻类学科组同伴们在实验过程中给予的宝贵意见和建议, 同 时感谢藻类环境生物学学科组提供相关的实验仪器, 保证实验顺利完成. 在此一并表示哀心的感谢. 


\section{4 参考文献}

[1] 林 蔡, 彭 欣, 吴忠兴等. 我国水华蓝藻的新类群——阿氏浮丝藻(Planktothrix agardhii)生理特性. 湖泊科学, 2008, 20(4): 437-442.

[2] 何家苑, 何振荣, 郭琼林. 有毒铜绿微囊藻对鱼和溞的毒性. 湖泊科学, 1997, 9(1): 49-56.

[3] Beaulieu SE, Sengco MR, Anderson DM. Using clay to control harmful algal blooms: deposition and resuspension of clay/algal flocs. Harmful Algae, 2005, 4(1): 123-138.

[4] Han MY, Kim W. A theoretical consideration of algae removal with clays. Microchemical Journal, 2001, 68(2-3): 157-161.

[5] 邹 华, 潘 纲, 陈 影. 壳聚糖改性粘土对水华优势澡铜绿微囊藻的絮凝去除. 环境科学, 2004, 25(6): 40-43.

[6] Zou H, Pan G, Chen H et al. Removal of cyanobacterial blooms in Taihu Lake using local. II. Effective removal of Microcystis aeruginosa using local soils and sediments modified by chitosan. Environmental Pollution, 2006, 141(2): 201-205.

[7] Pan G, Zou H, Chen H et al. Removal of harmful cyanobacterial blooms in Taihu Lake using local soils. III. Factors affecting the removal efficiency and an in situ field experiment using chitosan-modified local soils. Environmental Pollution, 2006, 141(2): 206-212.

[8] Divakaran R, Pillai VNS. Flocculation of kaolinite suspensions in water by chitosan. Water Research, 2001, 35(16): 3904-3908.

[9] Maxwell K, Johnson GN. Chlorophyll fluorescence-a practical guide. Journal of Experimental Botany, 2000, 51(345): 659-668.

[10] Pan G, Zhang MM, Chen H et al. Removal of cyanobacterial blooms in Taihu Lake using local soils. I. Equilibrium and kinetic screening on the flocculation of Microcystis aeruginosa using commercially available clays and minerals. Environmental Pollution, 2006, 141(2): 195-200

[11] Masojidek J. Physiological and molecular responses of algae to extreme conditions. Nova Hedwigia, 2001, 123: 499-500.

[12] Bolhàr-Nordenkampf HR, Long SP, Baker NR et al. Chlorophyll fluorescence as a probe of the photosynthetic competence of leaves in the field: A review of current instrumentation. Functional Ecology, 1989, 3(4): 497-514.

[13] Demmig B, Winter K, Krüger A et al. Zeaxanthin and the heat dissipation of excess light energy in Nerium oleander exposed to a combination of high light and water stress. Plant Physiology, 1988, 87(1): 17-24.

[14] Ralph PJ, Gademann R. Rapid light curves: A powerful tool to assess photosynthetic activity. Aquatic Botany, 2005, 82(3): 222-237.

[15] 张木兰, 潘 纲, 陈 影等. 改性沉积物除藻对水质改善的效果研究. 环境科学学报, 2007, 27(1): 13-17.

[16] Divakaran R, Pillai VNS. Mechanism of kaolinite and titanium dioxide flocculation using chitosan-assistance by fulvic acids. Water Research, 2004, 38(8): 2135-2143. 